\title{
Depression comorbid with tuberculosis and its impact on health status: cross-sectional analysis of community-based data from 48 low- and middle-income countries
}

Ai Koyanagi ${ }^{1,2^{*}}$ (D), Davy Vancampfort ${ }^{3,4}$, André F. Carvalho ${ }^{5}$, Jordan E. DeVylder ${ }^{6}$, Josep Maria Haro ${ }^{1,2}$, Damiano Pizzol ${ }^{7}$, Nicola Veronese ${ }^{8,9}$ and Brendon Stubbs $s^{10,11,12}$

\begin{abstract}
Background: Depression in tuberculosis increases the risk for adverse health outcomes. However, little is known about comorbid depression and tuberculosis in the general population. Thus, we assessed the association between depression and tuberculosis, and the decrements in health status associated with this comorbidity in 48 low- and middle-income countries.

Methods: Cross-sectional, community-based data from the World Health Survey on 242,952 individuals aged $\geq 18$ years were analyzed. Based on the World Mental Health Survey version of the Composite International Diagnostic Interview, past 12-month depression was categorized into depressive episode, brief depressive episode, subsyndromal depression, and no depression. Health status across six domains (cognition, interpersonal activities, sleep/energy, self-care, mobility, pain/discomfort) was assessed. Multivariable logistic and linear regression analyses were performed to assess the associations.

Results: The prevalence of depressive episode among those with and without tuberculosis was $23.7 \%$ and $6.8 \%$, respectively $(P<0.001)$. Tuberculosis was associated with a 1.98 (95\% Cl 1.47-2.67), 1.75 (95\% Cl 1.26-2.42), and 3.68 ( $95 \%$ Cl 3.01-4.50) times higher odds for subsyndromal depression, brief depressive episode, and depressive episode, respectively. Depressive episode co-occurring with tuberculosis was associated with significantly worse health status across all six domains compared to tuberculosis alone. Interaction analysis showed that depression significantly amplifies the association between TB and difficulties in self-care but not in other health domains.

Conclusions: Depression is highly prevalent in adults with tuberculosis, and is associated with worse health status compared to tuberculosis without depression. Public health efforts directed to the recognition and management of depression in people with tuberculosis may lead to better outcomes.
\end{abstract}

Keywords: Tuberculosis, Depression, Low- and middle-income countries, Epidemiology

\footnotetext{
* Correspondence: a.koyanagi@pssjd.org

${ }^{1}$ Research and Development Unit, Parc Sanitari Sant Joan de Déu, Universitat

de Barcelona, Fundació Sant Joan de Déu, Dr. Antoni Pujadas, 42, Sant Boi

de Llobregat, Barcelona, Spain

${ }^{2}$ Instituto de Salud Carlos III, Centro de Investigación Biomédica en Red de

Salud Mental, CIBERSAM, Madrid, Spain

Full list of author information is available at the end of the article
} 


\section{Background}

Tuberculosis (TB) is one of the top 10 causes of deaths globally [1]. In 2015, there were 10.4 million new TB cases and 1.8 million deaths due to TB. Over $95 \%$ of TB cases and deaths occur in developing countries [1]. Depression often coexists with TB [2], and this comorbidity is associated with poor adherence to $\mathrm{TB}$ treatment and higher mortality [3]. Lack of adherence to anti-TB regimens may lead to higher risk for drug resistance, morbidity, and mortality, as well as community exposure to TB $[4,5]$.

In low- and middle-income countries (LMICs), the prevalence of depression is high and may be increasing [6]. A recent large prospective study from Korea found that depression at baseline is associated with a higher risk for incident TB [7]. Depression may lead to an increased susceptibility to TB by compromising immunity or through neglected self-care [8]. Thus, depression may be an unrecognized driver of the global $\mathrm{TB}$ and multidrug resistant TB (MDR-TB) epidemics [2]. However, the few previous studies on the association between depression and TB from LMICs have only been conducted in clinical settings with small sample sizes, and information from the general population is lacking. Furthermore, there is limited information on the joint effect of $\mathrm{TB}$ and depression on health status. We therefore assessed the association between TB and depression, and whether the co-occurrence of TB and depression confers a more pronounced decrement in health status and function compared to TB alone using community-based, predominantly nationally representative data from 48 LMICs that participated in the World Health Survey (WHS). Epidemiological data on the $\mathrm{TB} /$ depression comorbidity and its effect on health outcomes are crucial to provide a more accurate assessment of the public health significance of this comorbidity.

\section{Methods}

\section{The survey}

The WHS was a cross-sectional survey carried out in 70 countries from 2002 to 2004. Survey details are available elsewhere (http://www.who.int/healthinfo/survey/en/). Briefly, single-stage random sampling and stratified multi-stage random cluster sampling was conducted in 10 and 60 countries, respectively. Eligible participants were those with a valid home address and aged $\geq$ 18 years. One individual was randomly chosen from the household with the use of Kish tables. The questionnaire was subject to standard translation procedures to ensure comparability between countries. Face-to-face interviews were conducted by trained interviewers. The overall individual response rate was 98.5\% [9]. To adjust for non-response, sampling weights were generated using the population distribution as reported by the United Nations Statistical Division. Ethical approval for the survey was provided by ethical boards at each study site. All participants gave their informed consent.

\section{Variables \\ $T B$}

Because the WHS did not include mycobacterial culture or sputum smear examinations, TB was based on past 12-month symptoms of active TB. Specifically, as in previous WHS publications [10-12], those who had both (1) a cough that lasted for 3 weeks or longer and (2) blood in phlegm (or coughed up blood) were considered to have active TB. Previous studies have shown that the presence of these typical symptoms are likely to have a sensitivity and specificity of $65-70 \%$ and $55-75 \%$, respectively, in the detection of $\mathrm{TB}$ [10].

\section{Depression}

The severity of depressive symptoms was established based on the individual questions of the World Mental Health Survey version of the Composite International Diagnostic Interview, which assessed the duration and persistence of depressive symptoms in the past 12 months [13]. Following the algorithms used in a previous WHS publication [14], four mutually exclusive groups were established based on the ICD-10 Diagnostic Criteria for Research (ICD-10-DCR) [15], where criterion $\mathrm{B}$ referred to symptoms of depressed mood, loss of interest, and fatigability. The algorithms used to define the four mutually exclusive groups were the following:

\section{Depressive episode group}

At least two criterion B symptoms with a total of at least four depressive symptoms lasting 2 weeks most of the day or all of the day.

Brief depressive episode group

Same criteria as depressive episode but did not meet the 2-week duration criterion.

Subsyndromal depression

At least one criterion B symptom with the total number of symptoms being three or less. The criteria of duration of at least 2 weeks and presence of symptoms during most of the day had to be met.

No depressive disorder group

None of the above.

In some analyses, we also dichotomized this variable as the absence or presence of depressive episode.

\section{Health status}

Health status was assessed with the use of 12 healthrelated questions pertaining to six different domains, namely (1) mobility, (2) pain and discomfort, (3) self-care, (4) cognition, (5) interpersonal activities, and (6) sleep and energy. These domains correspond to frequently used 
health outcome measures including the Short Form 12 [16], the Health Utilities Index Mark 3 [17], and the EuroQol 5D [18], and have been used as indicators of health status in prior WHS studies $[19,20]$. Each domain consisted of two questions that assessed health function in the past 30 days. The actual questions can be found in Additional file 1: Table S1. Each item was scored on a five-point scale ranging from 'none' to 'extreme/cannot do'. For each separate domain, we used factor analysis with polychoric correlations to obtain a factor score which was later converted to scores ranging from 0 to 100 with higher values representing worse health function [20].

\section{Control variables}

The selection of the control variables were based on past literature [10]. Sociodemographic variables included age, sex, education (no formal education, primary education, secondary or high school completed, or tertiary education completed), wealth, household size, and setting (rural or urban). Principal component analysis based on 15-20 assets was conducted to establish country-wise wealth quintiles. Current smoking was dichotomized as 'Yes' and 'No'. Respondents were asked how many standard drinks of any alcoholic beverage they had on each day of the past 7 days. Females who reported consuming at least four drinks, and males who reported consuming at least five drinks, on 1 or 2 days in the past 7 days were considered infrequent heavy drinkers, and respondents who drank these amounts at least 3 days in the past 7 days were considered frequent heavy drinkers. All other respondents, apart from lifetime abstainers, were considered non-heavy drinkers [21, 22]. Body mass index (BMI; $\left.\mathrm{kg} / \mathrm{m}^{2}\right)$ was based on self-reported weight and height, and was categorized as $<18.5$ (underweight), 18.5-24.9 (normal weight), 25.0-29.9 (overweight), and $\geq 30$ (obese). Diabetes was based on self-reported diagnosis.

\section{Statistical analysis}

Publically available data of the WHS included 69 countries. The data were nationally representative for all countries with the exception of China, Comoros, the Republic of Congo, Ivory Coast, India, and Russia. We excluded 10 countries as they lacked sampling information. A further 10 high-income countries were deleted as the focus of the study was on LMICs. Finally, Turkey was deleted due to lack of information on education and diabetes. Thus, a total of 48 countries, of which $21(\mathrm{n}=105,286)$ and $27(\mathrm{n}=137,666)$ were lowincome and middle-income countries, respectively, at the time of the survey (2003) according to the World Bank, were included in the final sample. According to the United Nations' classification system (http://unstats.un.org/unsd/ methods/m49/m49regin.htm), these corresponded to 20 countries in Africa $(n=82,424), 6$ in the Americas $(\mathrm{n}=62,732), 13$ in Asia $(\mathrm{n}=81,633)$, and 9 in Europe
( $\mathrm{n}=16,163$ ). Information on the individual countries is provided in Additional file 1: Table S2.

Statistical analyses were performed with Stata 14.1 (Stata Corp LP, College station, Texas). Descriptive analyses included unweighted Ns, and weighted proportions and means.

First, in order to assess the association between TB (exposure) and depression (subtypes; outcome), we conducted multivariable multinomial logistic regression analyses using the overall sample. We also assessed the association between TB (exposure) and depressive episode (outcome) using multivariable binary logistic regression while stratifying by region (Africa, Americas, Asia, Europe) or country income level (low-income, middle-income). For these stratified analyses, we could not assess all depression subtypes as the outcome as the number of individuals with TB was small in some subsamples.

Next, we created a four-category variable based on the presence or absence of depressive episode and TB, namely (1) no depression and no TB ( $\mathrm{n}=183,455)$; (2) depression without TB $(\mathrm{n}=11,440)$; (3) TB without depression ( $n=2617)$; and (4) TB with depression $(n=687)$, to assess whether TB with depression is associated with a larger decrement in health status as compared with TB alone. We conducted multivariable linear regression with this this four-category variable as the exposure and the six health status variables as the outcomes (mobility, pain/discomfort, self-care, cognition, interpersonal activities, sleep/ energy). We also conducted age-stratified analyses to assess whether the TB and depressive episode comorbidity have different effects on health status by age groups. Age was categorized as 18-44 (young adults; 67.8\%), 45-64 (middleaged adults; 23.6\%), and $\geq 65$ (older adults; 8.6\%) years, broadly representing distinct life stages [23]. In order to assess whether there is effect modification by depressive episodes in the association between TB and health status, we also conducted interaction analysis by including an interaction term in the model using the overall sample (TB $\times$ depressive episode). We did not conduct interaction analysis by age groups due to the small sample size and possibility for lack of statistical power.

All regression analyses were adjusted for age, sex, education, wealth, household size, location, smoking, alcohol consumption, BMI, diabetes, and country. Adjustment for country was performed by including dummy variables in the models, as in previous WHS publications [11, 19]. All variables were included in the models as categorical variables with the exception of age, household size, and the six variables on health status (continuous variables). The sample weighting and the complex study design were taken into account in all analyses. Results from the logistic and linear regression are presented as odds ratios (ORs) and bcoefficients, respectively, with $95 \%$ confidence intervals (CIs). The level of statistical significance was set at $P<0.05$. 
Under $10 \%$ of the data were missing for the variables used in the analysis with the exception of TB (17.7\%), BMI (30.3\%), and diabetes (12.6\%). For the regression analyses, we conducted multiple imputation of missing values using the $m i$ commands in Stata using chained equations (20 imputations) [24]. This method uses information from all other variables except the one being imputed to impute missing values. The variables included in the imputation model were the outcome and all other covariates [12]. The results based on complete case analysis were similar.

\section{Results}

The analytical sample consisted of 242,952 individuals with a mean (SD) age of 38.4 (16.1) years and $50.8 \%$ were women (Table 1$)$. The prevalence $(95 \% \mathrm{CI})$ of TB was $1.7 \%(1.5-1.8 \%)$. All types of depression were more frequent among those with $\mathrm{TB}$, with the difference being particularly pronounced for depressive episode (Fig. 1).

The prevalence of depressive episode among those with and without TB was $23.7 \%$ (95\% CI 20.5-27.1\%) and $6.8 \%$ (95\% CI $6.5-7.1 \%)$, respectively ( $\chi^{2}$ test $\left.P<0.001\right)$. The results of the multivariable multinomial logistic regression using the overall sample showed that TB is associated with a 1.98 (95\% CI 1.47-2.67), 1.75 (95\% CI 1.26-2.42), and 3.68 (95\% CI 3.01-4.50) times higher odds for subsyndromal depression, brief depressive episode, and depressive episode, respectively (Table 2). Older age, female sex, lower levels of wealth, smoking, and diabetes were significant correlates of depressive episode.

The association between TB and depressive episode estimated by multivariable binary logistic regression by regions or country income levels are shown in Table 3. TB was associated with a depressive episode across regions and county income levels although the estimates for Europe did not reach statistical significance, possibly due to lack of statistical power (OR, 2.67; 95\% CI 0.75-9.52; $P=0.1293)$.

Compared to those with no TB or depressive episode, depression alone, TB alone, and comorbid TB/depression were all significantly associated with worse health status scores in all domains. Comorbid TB/depression was associated with the largest decline (Table 4).

The results of the age-stratified analyses are shown in Additional file 1: Table S3. The decline in health status associated with depression alone and cooccurring TB/depression was similar across age groups, but that of TB alone was less pronounced in the oldest age group (i.e., $\geq 65$ years). In order to assess whether the difference between $\mathrm{TB}$ alone and comorbid $\mathrm{TB} /$ depression is statistically significant, we also conducted the same analysis but changing the reference category to $\mathrm{TB}$ alone (overall sample). The b-coefficients (95\% CIs) for comorbid TB/depression (vs. TB alone) were mobility 19.17 (14.52-23.81), self-
Table 1 Sample characteristics

\begin{tabular}{|c|c|c|c|}
\hline Characteristic & Category & $\begin{array}{l}\text { Unweighted } \\
\mathrm{N}\end{array}$ & $\begin{array}{l}\% \text { or Mean } \\
(\mathrm{SD})\end{array}$ \\
\hline \multirow[t]{2}{*}{ Tuberculosis } & No & 196,417 & 98.3 \\
\hline & Yes & 3347 & 1.7 \\
\hline \multirow[t]{4}{*}{ Depression } & No depression & 205,752 & 87.7 \\
\hline & $\begin{array}{l}\text { Subsyndromal } \\
\text { depression }\end{array}$ & 5238 & 2.6 \\
\hline & $\begin{array}{l}\text { Brief depressive } \\
\text { episode }\end{array}$ & 6674 & 2.9 \\
\hline & Depressive episode & 13,965 & 6.9 \\
\hline Age, years & Mean (SD) & 233,879 & $38.4(16.1)$ \\
\hline \multirow[t]{2}{*}{ Sex } & Male & 104,355 & 49.2 \\
\hline & Female & 129,448 & 50.8 \\
\hline \multirow[t]{4}{*}{ Education } & No formal & 52,116 & 26.5 \\
\hline & Primary & 76,193 & 30.9 \\
\hline & Secondary & 86,740 & 33.5 \\
\hline & Tertiary & 17,860 & 9.2 \\
\hline \multirow[t]{5}{*}{ Wealth } & Poorest & 51,599 & 20.1 \\
\hline & Poorer & 45,893 & 20.0 \\
\hline & Middle & 42,317 & 19.9 \\
\hline & Richer & 40,128 & 20.0 \\
\hline & Richest & 37,724 & 20.0 \\
\hline Household size & Mean (SD) & 242,311 & $5.7(3.0)$ \\
\hline \multirow[t]{2}{*}{ Setting } & Rural & 117,556 & 56.5 \\
\hline & Urban & 114,825 & 43.5 \\
\hline \multirow[t]{2}{*}{ Current smoking } & No & 174,814 & 73.5 \\
\hline & Yes & 54,746 & 26.5 \\
\hline \multirow{4}{*}{$\begin{array}{l}\text { Alcohol } \\
\text { consumption }\end{array}$} & Lifetime abstainer & 142,282 & 66.4 \\
\hline & Non-heavy & 74,016 & 28.8 \\
\hline & Infrequent heavy & 8817 & 3.7 \\
\hline & Frequent heavy & 2411 & 1.0 \\
\hline \multirow{4}{*}{$\begin{array}{l}\text { Body mass index, } \\
\mathrm{kg} / \mathrm{m}^{2}\end{array}$} & $<18.5$ & 16,883 & 13.8 \\
\hline & $18.5-24.9$ & 95,208 & 57.9 \\
\hline & $25.0-29.9$ & 38,700 & 19.3 \\
\hline & $\geq 30.0$ & 18,287 & 9.0 \\
\hline \multirow[t]{2}{*}{ Diabetes } & No & 205,671 & 97.0 \\
\hline & Yes & 6537 & 3.0 \\
\hline
\end{tabular}

Data are unweighted $\mathrm{N}$ and weighted proportion or mean (SD) $S D$ standard deviation

care 18.46 (13.41-23.54), pain/discomfort 20.14 (16.23-24.04), cognition 15.61 (11.13-20.09), interpersonal activities $15.04(10.13-19.96)$, and sleep/energy 19.67 (14.47-24.88) (all $P<0.0001)$. Overall, the interaction analysis showed that depression significantly amplifies the association between TB and difficulties in self-care but not with other health domains (Additional file 1: Table S4). 


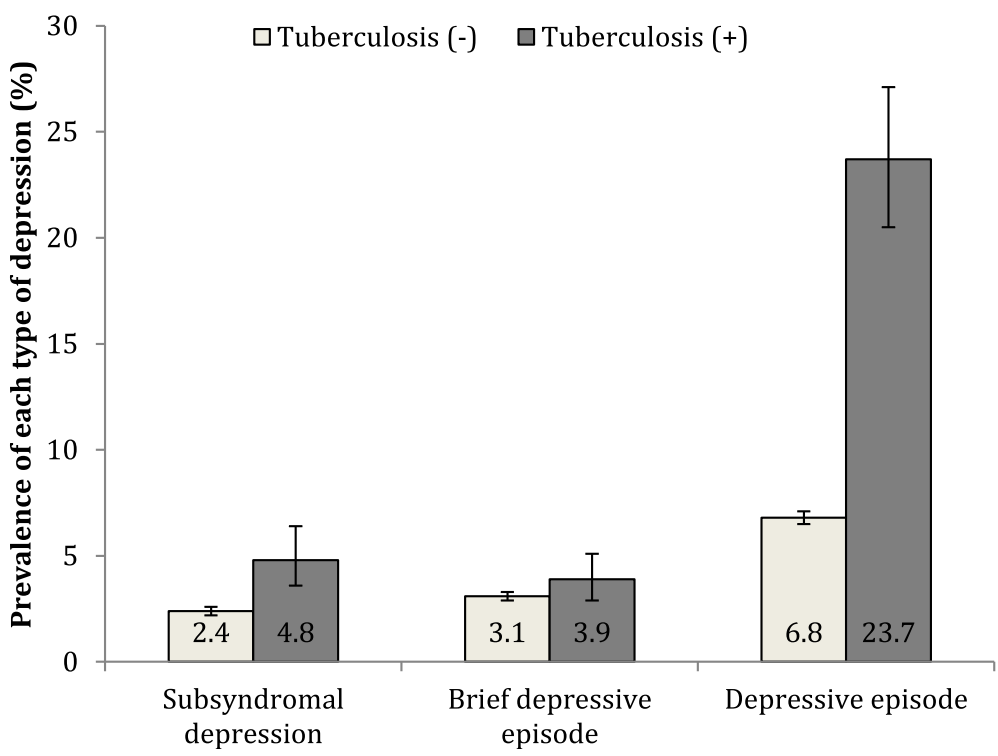

Fig. 1 Prevalence of each type of depression by the presence or absence of tuberculosis. Bars denote 95\% confidence intervals. Estimates are based on weighted sample

Table 2 Association of tuberculosis and other covariates with depression estimated by multivariable multinomial logistic regression

\begin{tabular}{|c|c|c|c|c|c|c|c|}
\hline \multirow[b]{3}{*}{ Characteristic } & \multirow[b]{3}{*}{ Category } & \multicolumn{6}{|c|}{ Depression subtypes (Reference $=$ No depression) } \\
\hline & & \multicolumn{2}{|c|}{ Subsyndromal depression } & \multicolumn{2}{|c|}{ Brief depressive episode } & \multicolumn{2}{|c|}{ Depressive episode } \\
\hline & & $\overline{\mathrm{OR}}(95 \% \mathrm{Cl})$ & $P$ value & $\overline{\mathrm{OR}}(95 \% \mathrm{Cl})$ & $P$ value & $\overline{\mathrm{OR}}(95 \% \mathrm{Cl})$ & $P$ value \\
\hline Tuberculosis & Yes vs. No & $1.98(1.47-2.67)$ & $<0.0001$ & $1.75(1.26-2.42)$ & 0.0008 & $3.68(3.01-4.50)$ & $<0.0001$ \\
\hline Age, years & Per unit increase & $1.02(1.02-1.03)$ & $<0.0001$ & $1.01(1.00-1.01)$ & 0.0003 & $1.02(1.02-1.02)$ & $<0.0001$ \\
\hline Sex & Female vs. Male & $1.84(1.60-2.12)$ & $<0.0001$ & $2.19(1.94-2.46)$ & $<0.0001$ & $2.06(1.87-2.27)$ & $<0.0001$ \\
\hline \multirow[t]{4}{*}{ Education } & No formal & 1.00 & & 1.00 & & 1.00 & \\
\hline & Primary & $0.86(0.72-1.03)$ & 0.1101 & $0.95(0.82-1.10)$ & 0.4629 & $0.92(0.83-1.03)$ & 0.1414 \\
\hline & Secondary & $0.76(0.61-0.94)$ & 0.0133 & $0.98(0.81-1.18)$ & 0.8148 & $0.77(0.67-0.88)$ & 0.0001 \\
\hline & Tertiary & $0.83(0.53-1.30)$ & 0.4073 & $0.80(0.62-1.02)$ & 0.0686 & $0.82(0.53-1.25)$ & 0.3464 \\
\hline \multirow[t]{5}{*}{ Wealth } & Poorest & 1.00 & & 1.00 & & 1.00 & \\
\hline & Poorer & $1.00(0.80-1.25)$ & 0.9855 & $0.98(0.84-1.16)$ & 0.8384 & $0.95(0.85-1.07)$ & 0.4023 \\
\hline & Middle & $1.07(0.86-1.34)$ & 0.5281 & $0.90(0.76-1.06)$ & 0.2022 & $0.96(0.84-1.08)$ & 0.4651 \\
\hline & Richer & $1.05(0.81-1.36)$ & 0.7289 & $0.97(0.82-1.16)$ & 0.7557 & $0.87(0.76-1.00)$ & 0.0486 \\
\hline & Richest & $0.90(0.64-1.26)$ & 0.5175 & $0.80(0.66-0.97)$ & 0.0229 & $0.69(0.57-0.83)$ & 0.0001 \\
\hline Household size & Per unit increase & $1.03(1.00-1.06)$ & 0.0296 & $1.01(0.98-1.03)$ & 0.4946 & $1.01(0.99-1.04)$ & 0.2889 \\
\hline Setting & Urban vs. Rural & $0.93(0.79-1.11)$ & 0.4373 & $1.12(0.98-1.28)$ & 0.0978 & $1.05(0.94-1.17)$ & 0.4040 \\
\hline Current smoking & Yes vs. No & $1.31(1.10-1.55)$ & 0.0026 & $1.26(1.10-1.44)$ & 0.0007 & $1.29(1.14-1.45)$ & $<0.0001$ \\
\hline \multirow[t]{4}{*}{ Alcohol consumption } & Lifetime abstainer & 1.00 & & 1.00 & & 1.00 & \\
\hline & Non-heavy & $1.27(1.09-1.47)$ & 0.0026 & $1.51(1.32-1.73)$ & $<0.0001$ & $1.10(0.99-1.22)$ & 0.0685 \\
\hline & Infrequent heavy & $1.45(1.02-2.06)$ & 0.0407 & $1.72(1.29-2.28)$ & 0.0002 & $1.03(0.83-1.29)$ & 0.7845 \\
\hline & Frequent heavy & $2.10(1.15-3.85)$ & 0.0159 & $1.85(1.18-2.92)$ & 0.0080 & $1.14(0.79-1.65)$ & 0.4887 \\
\hline \multirow[t]{4}{*}{ Body mass index, $\mathrm{kg} / \mathrm{m}^{2}$} & $<18.5$ & $1.02(0.76-1.36)$ & 0.8991 & $1.01(0.83-1.23)$ & 0.8988 & $1.08(0.90-1.31)$ & 0.4065 \\
\hline & $18.5-24.9$ & 1.00 & & 1.00 & & 1.00 & \\
\hline & $25.0-29.9$ & $1.10(0.89-1.36)$ & 0.3673 & $0.96(0.83-1.11)$ & 0.5485 & $0.99(0.88-1.11)$ & 0.8586 \\
\hline & $\geq 30.0$ & $1.09(0.84-1.41)$ & 0.5230 & $1.05(0.86-1.29)$ & 0.6136 & $1.05(0.91-1.22)$ & 0.4831 \\
\hline Diabetes & Yes vs. No & $1.14(0.84-1.54)$ & 0.4000 & $1.39(1.09-1.76)$ & 0.0076 & $1.91(1.62-2.24)$ & $<0.0001$ \\
\hline
\end{tabular}


Table 3 Association between tuberculosis (exposure) and depressive episode (outcome) by regions or country income level

\begin{tabular}{lll}
\hline Region or country income level & OR $(95 \% \mathrm{Cl})$ & $P$ value \\
\hline Africa & $3.50(2.76-4.43)$ & $<0.0001$ \\
Americas & $2.74(1.80-4.18)$ & $<0.0001$ \\
Asia & $3.75(2.74-5.14)$ & $<0.0001$ \\
Europe & $2.67(0.75-9.52)$ & 0.1293 \\
Low-income countries & $3.52(2.74-4.54)$ & $<0.0001$ \\
Middle-income countries & $3.24(2.40-4.35)$ & $<0.0001$
\end{tabular}

Estimates are based on multivariable logistic regression

Models are adjusted for age, sex, education, wealth, household size, location, smoking, alcohol consumption, body mass index, diabetes, and country $O R$ odds ratio, $\mathrm{Cl}$ confidence interval

\section{Discussion}

We found that TB is associated with the entire depression spectrum in the overall sample, and that the association between TB and depressive episode is comparable across regions and country income levels. Furthermore, the co-occurrence of depression and TB was associated with a major decrement in all health domains assessed compared to TB alone, with this additive effect being particularly pronounced for difficulties in self-care. The strengths of the study include the large sample size and use of predominantly nationally representative data from approximately one-fourth of the countries in the world obtained by standardized questionnaires across all countries. To the best of our knowledge, this is the first general population study on TB and depression. Furthermore, it is one of the very few studies assessing the association between $\mathrm{TB}$ and depression severity, and is the first to assess the joint effect of TB and depression on a variety of health conditions (i.e., mobility, self-care, pain/ discomfort, cognition, interpersonal activities, sleep/energy). The finding that there may be a synergistic effect between $\mathrm{TB}$ and depression in terms of some health outcomes (i.e., self-care) is novel.

The association between TB and depression may be bidirectional $[7,25]$. Depression itself may compromise immunity, leading to an increased risk for TB [8], while increased inflammation in TB may increase risk for depression [26]. Alternatively, depression may be a psychological reaction to the symptoms of TB (e.g., chronic cough, fatigue, weight loss) or associated disability [27], while hypoxia in chronic pulmonary diseases may induce depression [28]. It is also possible that patients with $\mathrm{TB}$ are perceived as a source of contagion in the community, which may lead to discrimination, stigma, social isolation, and rejection, and may predispose individuals to a higher risk for depression [27, 29]. Further, some anti-TB drugs can induce depression [27]. Finally, common risk factors, such as compromised immunity, stress, and malnutrition, may underlie the association $[8,26,30,31]$. Regardless of whether depression and TB are etiologically related, the mere co-existence can complicate the diagnosis and management of these conditions, while it is also possible that they mutually influence each other and lead to the exacerbation of the other, altering the clinical course [27].

Other factors which were identified as significant correlates of a depressive episode in our study included sociodemographic factors (older age, female sex, lower levels of wealth), smoking, and diabetes. Previous studies have also found these factors to be associated with depression [32-36]. In particular, diabetes is known to increase risk for TB [37], and may be an important risk factor for TB in LMICs [10] as there is an upward trend in diabetes prevalence mainly driven by changes in lifestyles and diet in this setting [38]. On the other hand, diabetes and depression are often comorbid and common pathophysiological mechanisms (e.g., stress, inflammation) may underlie this co-occurrence [39].

In our study, compared to TB occurring in isolation, co-existing $\mathrm{TB} /$ depression was associated with decrements in all health domains assessed, while a significant interaction was observed for difficulties in self-care. These results are in line with a small cross-sectional study from Turkey showing that psychiatric comorbidity is associated with a higher rate of disability among TB patients [40]. Depression may lead to poor adherence to

Table 4 Association between TB/depressive episode groups and health status estimated by multivariable linear regression

\begin{tabular}{|c|c|c|c|c|c|c|}
\hline & TB (-) Depression (+) & & TB (+) Depression (-) & & TB (+) Depression (+) & \\
\hline & b-coefficient $(95 \% \mathrm{Cl})$ & $P$ value & b-coefficient ( $95 \%$ Cl) & $P$ value & b-coefficient (95\% Cl) & $P$ value \\
\hline Mobility & $15.92(14.81-17.04)$ & $<0.0001$ & $8.63(6.55-10.71)$ & $<0.0001$ & $27.80(23.60-31.99)$ & $<0.0001$ \\
\hline Self-care & $11.96(10.78-13.13)$ & $<0.0001$ & $5.34(3.20-7.48)$ & $<0.0001$ & $23.80(19.11-28.49)$ & $<0.0001$ \\
\hline Pain/discomfort & $18.70(17.39-20.00)$ & $<0.0001$ & $10.27(8.24-12.30)$ & $<0.0001$ & $30.41(26.97-33.84)$ & $<0.0001$ \\
\hline Cognition & $16.55(15.26-17.83)$ & $<0.0001$ & $8.63(6.35-10.91)$ & $<0.0001$ & $24.24(20.19-28.28)$ & $<0.0001$ \\
\hline Interpersonal activities & $12.69(11.53-13.86)$ & $<0.0001$ & $4.41(2.34-6.48)$ & $<0.0001$ & $19.45(14.81-24.09)$ & $<0.0001$ \\
\hline Sleep/energy & $19.61(18.37-20.85)$ & $<0.0001$ & $10.32(7.94-12.70)$ & $<0.0001$ & $29.99(25.30-34.68)$ & $<0.0001$ \\
\hline
\end{tabular}

Reference category is TB (-) Depression (-)

Health status was the outcome and scores ranged from 0 to 100 with higher scores corresponding to worse health status

Models are adjusted for age, sex, education, wealth, household size, location, smoking, alcohol consumption, body mass index, diabetes, and country

$T B$ tuberculosis, $\mathrm{Cl}$ confidence interval 
anti-TB drugs, and thereby exacerbate the symptoms of $\mathrm{TB}$ and its associated disability. Indeed, a prospective study from Peru showed that co-occurring TB/depression leads to lower adherence to $\mathrm{TB}$ treatment and higher mortality when compared to TB without depression [3]. The fact that a significant interaction was observed for self-care may imply that there is a synergistic effect between TB and depression. It may be hypothesized, for example, that depression leads to poor TB treatment adherence and exacerbation of symptoms, which in turn may lead to a worsening of depression. However, the precise underlying mechanisms or the reason why an interaction was only observed for self-care is unclear and warrants further investigation. Finally, delayed diagnosis of TB in people with depression may also partly explain our findings. It has been reported that delayed detection of physical diseases may be common in individuals with depression [41]. Thus, it may be that, when individuals with prior depression are diagnosed with $\mathrm{TB}$, their TB symptoms are more severe compared to those without prior depression. Lack of motivation or social support and cognitive impairment, which may affect decision-making [42], might limit access to healthcare among depressed individuals, leading to delayed diagnosis and treatment initiation for TB.

Previous studies have shown that treating the psychological aspects of TB may lead to better clinical outcomes. For example, a prospective controlled trial in India showed that psychotherapy during $\mathrm{TB}$ treatment leads to higher adherence, treatment, and cure rates [43]. Furthermore, a psychological support group intervention for patients with MDR-TB in Peru showed that such an intervention can improve treatment adherence and completion [44]. Additionally, the formation of 'TB clubs' in Ethiopia increased treatment completion rates and reduced the stigma associated with TB [45]. Recently, a randomized controlled trial in Ethiopia showed that psychological counseling and educational intervention can substantially improve treatment adherence rates in TB [46].

A multi-faceted approach is likely to be relevant in addressing comorbid depression and TB in LMICs. First, previous studies from LMICs have shown that the treating doctor is often not aware of co-existing psychiatric morbidity in TB patients [47]. Thus, training of medical professionals and students on the psychological aspects of TB may lead to early detection and better management of psychiatric complications, and ultimately to a better clinical outcome of TB. Next, a close collaboration between TB and mental health specialists would be important for the early detection and treatment of depression in TB. Previous studies have shown that training of non-mental health specialists in LMICs may only have a limited impact on depression detection rates [48]. Thus, screening for depression may be a cost-effective strategy to improve detection rates of depression in TB. However, symptoms specific to depression (e.g., low mood, anhedonia) and symptoms of depression that overlap with TB (e.g., fatigue) should be distinguished. Some studies have assessed the validity of depression screeners such as the Center for Epidemiological Studies Depression scale or the General Health Questionnaire 12 among TB patients $[40,49]$. These studies found that these screening tools can be used among TB patients to detect depression but that there may be a disease-specific optimal cut-off. Future studies on the validity and reliability of such screening tools are warranted, as only scarce data from limited populations are currently available. Finally, patient education and community awareness regarding facts and myths of TB may also be important [50], as discrimination and stigma can be underlying causes of depression in TB.

Our results should be interpreted in the light of several limitations. First, we lacked information on HIV, which is known to be associated with higher risk for TB [1] and depression [51]. Thus, some of the association may be attributable to comorbid HIV. However, this may not have been a major limitation as our region-wise analysis showed that TB is associated with depression even in areas with very low HIV prevalence (e.g., the Americas). Second, our study was based on the symptoms of TB rather than a laboratory confirmed diagnosis. Although we used the identical definition for TB used in previous publications [10-12], it is possible that some level of symptom overlap may exist between respiratory diseases such as pneumonia, bronchitis, and chronic obstructive pulmonary disease, which may also cause cough of long duration and hemoptysis. Thus, our estimates may partially be representing the association between these conditions and depression. Furthermore, the potential misclassification may have led to an underestimation of the association between TB and depression. However, it is reassuring that the prevalence of depression in TB was within the previously reported range of estimates among patients with confirmed TB [2]. Additionally, we are not aware of any other population-based data with such a large number of LMICs that can be used to investigate the TB-depression relationship. Third, high-risk groups, such as the institutionalized and homeless, were not included in our study and thus our findings are not generalizable to this population. Finally, the direction of causality cannot be established due to the cross-sectional design.

\section{Conclusions}

In conclusion, individuals with TB have higher odds for depression, and the co-occurrence of TB and depression is associated with decrements in health. Screening for and addressing depression in individuals with TB may lead to better clinical outcomes. However, mental health services and specialists are limited in low-resourced settings where the highest burden of TB is located. Increased recognition 
of co-existing depression in TB patients by health professionals and the use of non-specialist health workers trained in mental healthcare, especially in resourcelimited settings, may be key. However, given that healthcare workers are at increased risk of occupationally acquired TB in LMICs [52], sound infection control measures should be implemented to protect these individuals, yet this is a particular challenge in LMICs due to financial constraints. Finally, simultaneously addressing the mental and physical aspects of $\mathrm{TB}$ may lead to reduction in $\mathrm{TB}$ transmission [53], and also possibly in TB mortality and MDR-TB. This is an area for future research.

\section{Additional file}

Additional file 1: Table S1. Questions used to assess health status. Table S2. Countries included in the analysis and sample size. Table S3. Association between TB/depressive episode groups and health status by age groups estimated by multivariable linear regression. Table S4. Interaction effect of TB and depressive episode on health status. (DOCX $45 \mathrm{~kb}$ )

\section{Abbreviations}

BMI: body mass index; Cl: confidence intervals; LMIC: low- and middle-income countries; MDR-TB: multidrug resistant tuberculosis; OR: odds ratio;

TB: tuberculosis; WHS: World Health Survey

\section{Funding}

AK's work was supported by the Miguel Servet contract financed by the CP13/ 00150 and PI15/00862 projects, integrated into the National $R+D+I$ and funded by the ISCIII - General Branch Evaluation and Promotion of Health Research, and the European Regional Development Fund (ERDF-FEDER). BS receives funding from the National Institute for Health Research Collaboration for Leadership in Applied Health Research \& Care Funding scheme. The views expressed in this publication are those of the authors and not necessarily those of the NHS, the National Institute for Health Research, or the Department of Health. These funders had no role in the design of the study, collection, analysis, and interpretation of data, or in writing the manuscript.

\section{Availability of data and materials}

The dataset supporting the conclusions of this article is available (upon registration) from http://www.who.int/healthinfo/survey/en/.

\section{Authors' contributions}

AK conceived the study idea, analyzed and interpreted the data, and wrote the main body of the text. DV, AFC, JED, DP, JMH, NV, and BS contributed to the drafting of the manuscript, interpreted the data, and commented for intellectual content. All authors read and approved the final manuscript.

Ethics approval and consent to participate

Ethical approval was obtained from each of the following committees in the respective countries for the World Health Survey:

\begin{tabular}{|c|c|}
\hline Country & Ethical committee approving the study \\
\hline Bangladesh & Mitra and Associates \\
\hline $\begin{array}{l}\text { Bosnia and } \\
\text { Herzegovina }\end{array}$ & The Federal Public Health Institute \\
\hline Brazil & Fundacao Oswaldo Cruz \\
\hline Burkina Faso & Institut de Recherche en Sciences de la Santé \\
\hline Chad & Faculté des Sciences de la Santé, Univ N'Djamena \\
\hline China & Centre for Health Statistics Information \\
\hline Comoros & Bureau Comorien de Conseil \\
\hline
\end{tabular}

(Continued)

\begin{tabular}{|c|c|}
\hline Republic of congo & Unité de recherche sur les systèmes de santé \\
\hline Ivory Coast & Ministère de la Santé \\
\hline Croatia & The Croatian National Institute of Public Health \\
\hline Czech Republic & Institute of Health Information and Statistics \\
\hline Dominican Republic & Centro de Estudios Sociales y Demográficos (CESDEM) \\
\hline Ecuador & $\begin{array}{l}\text { Fundación Ecuatoriana para la Salud y el Desarrollo } \\
\text { (FESALUD) }\end{array}$ \\
\hline Estonia & Saar Poll Ltd. \\
\hline Ethiopia & Department of Community Health, Jimma University \\
\hline Georgia & Georgian State Medical Academy (GSMA) \\
\hline Ghana & $\begin{array}{l}\text { Department of Community Health, Ghana Medical } \\
\text { School }\end{array}$ \\
\hline Hungary & Johan Bela National Centre for Epidemiology \\
\hline India & International Institute of Population Sciences \\
\hline Kazakhstan & Kazakstan School of Public Health (KSPH) \\
\hline Kenya & Central Bureau of Statistics \\
\hline Laos & National Institute of Public Health, Ministry of Health \\
\hline Latvia & The Health Promotion Center \\
\hline Malawi & Centre for Social Research (CSR) \\
\hline Malaysia & Public Health Institute, Ministry of Health \\
\hline Mali & Cellule de Planification et de Statistique (CPS) \\
\hline Mauritania & Office Nationale de la Statistique (ONS) \\
\hline Mauritius & Mauritius Institute of Health \\
\hline Mexico & Instituto Nacional de Salud Pública \\
\hline Morocco & Ministère de la Santé \\
\hline Myanmar & Department of Medical Research, Ministry of Health \\
\hline Namibia & Ministry of Health \\
\hline Nepal & ORG-MARG Nepal PVT Ltd. \\
\hline Pakistan & Ministry of Health \\
\hline Paraguay & $\begin{array}{l}\text { Fac. de Ciencias Veterinarias, Universidad Nacional/ } \\
\text { DGEEC }\end{array}$ \\
\hline Philippines & College of Medicine, University of the Philippines \\
\hline Russia & Semashko Institute for Research on Social Hygiene \\
\hline Senegal & Direction Etudes, Recherche et Formation (DERF) \\
\hline Slovakia & Centre of Biostatistics and Environment \\
\hline South Africa & Community Agency for Social Enquiry (CASE) \\
\hline Sri Lanka & Ministry of Health \\
\hline Swaziland & Faculty of Health Sciences, University of Swaziland \\
\hline Tunisia & Institut National de la Santé Publique \\
\hline Ukraine & Odessa State Medical University \\
\hline Uruguay & Centro de Estudios de Economia y Salud (CEES) \\
\hline Vietnam & Ministry of Health \\
\hline Zambia & $\begin{array}{l}\text { School of Humanities \& Social Sciences, University of } \\
\text { Zambia }\end{array}$ \\
\hline Zimbabwe & Community Health, University of Zimbabwe \\
\hline
\end{tabular}




\section{Consent for publication}

Not applicable.

\section{Competing interests}

The authors declare that they have no competing interests.

\section{Publisher's Note}

Springer Nature remains neutral with regard to jurisdictional claims in published maps and institutional affiliations.

\section{Author details}

${ }^{1}$ Research and Development Unit, Parc Sanitari Sant Joan de Déu, Universitat de Barcelona, Fundació Sant Joan de Déu, Dr. Antoni Pujadas, 42, Sant Boi de Llobregat, Barcelona, Spain. ${ }^{2}$ Instituto de Salud Carlos III, Centro de Investigación Biomédica en Red de Salud Mental, CIBERSAM, Madrid, Spain. ${ }^{3} \mathrm{KU}$ Leuven Department of Rehabilitation Sciences, Leuven, Belgium. ${ }^{4} \mathrm{KU}$ Leuven, University Psychiatric Center KU Leuven, Leuven-Kortenberg, Belgium. ${ }^{5}$ Department of Clinical Medicine and Translational Psychiatry Research Group, Faculty of Medicine, Federal University of Ceará, Fortaleza, Brazil. ${ }^{6}$ Fordham University, Graduate School of Social Service, New York, NY, USA. ${ }^{7}$ Operation Research Unit, Doctors with Africa, Maputo, Mozambique. ${ }^{8}$ Institute for Clinical Research and Education in Medicine (IREM), Padova, Italy. ${ }^{9}$ National Research Council, Neuroscience Institute, Aging Branch, Padova, Italy. ${ }^{10}$ Physiotherapy Department, South London and Maudsley NHS Foundation Trust, Denmark Hill, London, UK. ${ }^{11}$ Health Service and Population Research Department, Institute of Psychiatry, Psychology and Neuroscience, King's College London, London, UK. ${ }^{12}$ Faculty of Health, Social Care and Education, Anglia Ruskin University, Chelmsford, UK.

\section{Received: 1 September 2017 Accepted: 9 November 2017}

\section{Published online: 28 November 2017}

\section{References}

1. World Health Organization. Tuberculosis. http://www.who.int/mediacentre/ factsheets/fs104/en/. Accessed 27 July 2017.

2. Sweetland $A$, Oquendo $M$, Wickramaratne $P$, Weissman $M$, Wainberg $M$. Depression: a silent driver of the global tuberculosis epidemic. World Psychiatry. 2014;13(3):325-6.

3. Ugarte-Gil C, Ruiz P, Zamudio C, Canaza L, Otero L, Kruger H, Seas C. Association of major depressive episode with negative outcomes of tuberculosis treatment. PLoS One. 2013;8(7):e69514.

4. Chaudhry LA, Zamzami M, Aldin S, Pazdirek J. Clinical consequences of noncompliance with directly observed therapy short course (DOTS): Story of a recurrent defaulter. Int J Mycobacteriol. 2012;1(2):99-103.

5. Kulkarni P, Akarte S, Mankeshwar R, Bhawalkar J, Banerjee A, Kulkarni A. Non-adherence of new pulmonary tuberculosis patients to anti-tuberculosis treatment. Ann Med Health Sci Res. 2013;3(1):67-74.

6. Patel V, Kleinman A. Poverty and common mental disorders in developing countries. Bull World Health Organ. 2003;81(8):609-15.

7. Oh KH, Choi H, Kim EJ, Kim HJ, Cho SI. Depression and risk of tuberculosis: a nationwide population-based cohort study. Int J Tuberc Lung Dis. 2017; 21(7):804-9.

8. Reiche EM, Nunes SO, Morimoto HK. Stress, depression, the immune system, and cancer. Lancet Oncol. 2004;5(10):617-25.

9. Nuevo R, Chatterji S, Verdes E, Naidoo N, Arango C, Ayuso-Mateos JL. The continuum of psychotic symptoms in the general population: a crossnational study. Schizophr Bull. 2012;38(3):475-85.

10. Goldhaber-Fiebert JD, Jeon CY, Cohen T, Murray MB. Diabetes mellitus and tuberculosis in countries with high tuberculosis burdens: individual risks and social determinants. Int J Epidemiol. 2011;40(2):417-28.

11. Stubbs B, Koyanagi A, Veronese N, Vancampfort D, Solmi M, Gaughran F, Carvalho AF, Lally J, Mitchell AJ, Mugisha J, et al. Physical multimorbidity and psychosis: comprehensive cross sectional analysis including 242,952 people across 48 low- and middle-income countries. BMC Med. 2016;14:189.

12. Vancampfort D, Koyanagi A, Ward P, Veronese N, Carvalho AF, Solmi M, Mugisha J, Rosenbaum S, De Hert M, Stubbs B. Perceived stress and its relationship with chronic conditions and multimorbidity among 229,293 community-dwelling adults in 44 low- and middle-income countries. Am J Epidemiol. 2017;186(8):979-89.

13. Kessler RC, Ustun TB. The World Mental Health (WMH) Survey Initiative Version of the World Health Organization (WHO) Composite
International Diagnostic Interview (CIDI). Int J Methods Psychiatr Res. 2004;13(2):93-121

14. Ayuso-Mateos JL, Nuevo R, Verdes E, Naidoo N, Chatterij S. From depressive symptoms to depressive disorders: the relevance of thresholds. Br J Psychiatry. 2010;196(5):365-71.

15. World Health Organization. The ICD-10 Classification of Mental and Behavioural Disorders: Diagnostic Criteria for Research. 1993. www.who.int/ classifications/icd/en/GRNBOOK.pdf. Accessed 15 Sept 2017.

16. Ware Jr J, Kosinski M, Keller SD. A 12-Item Short-Form Health Survey: construction of scales and preliminary tests of reliability and validity. Med Care. 1996:34(3):220-33.

17. Feeny D, Furlong W, Boyle M, Torrance GW. Multi-attribute health status classification systems. Health Utilities Index. Pharmacoeconomics. 1995; 7(6):490-502.

18. Kind P. The EuroQoL instrument: an index of health-related quality of life. In: Spilker B, editor. Quality of Life and Pharmacoeconomics in Clinical Trial. Philadelphia, PA: Lippincott-Raven Publishers; 1996. p. 191-201.

19. Koyanagi A, Oh H, Stickley A, Haro JM, DeVylder J. Risk and functional significance of psychotic experiences among individuals with depression in 44 low- and middle-income countries. Psychol Med. 2016;46(12):2655-65.

20. Stubbs B, Koyanagi A, Schuch F, Firth J, Rosenbaum S, Gaughran F, Mugisha J, Vancampfort D. Physical activity levels and psychosis: a mediation analysis of factors influencing physical activity target achievement among 204186 people across 46 low- and middle-income countries. Schizophr Bull. 2017:43(3):536-45.

21. Hosseinpoor AR, Bergen N, Kunst A, Harper S, Guthold R, Rekve D, d'Espaignet ET, Naidoo N, Chatterji S. Socioeconomic inequalities in risk factors for non communicable diseases in low-income and middle-income countries: results from the World Health Survey. BMC Public Health. 2012;12:912.

22. World Health Organization. International guide for monitoring alcohol consumption and related harm. Geneva: WHO; 2002.

23. Timsina LR, Willetts JL, Brennan MJ, Marucci-Wellman H, Lombardi DA, Courtney TK, Verma SK. Circumstances of fall-related injuries by age and gender among community-dwelling adults in the United States. PLoS One. 2017;12(5):e0176561.

24. StataCorp. http://www.stata.com/manuals13/mimiimputechained.pdf. Accessed 15 Sept 2017.

25. Yen YF, Chung MS, Hu HY, Lai YJ, Huang LY, Lin YS, Chou P, Deng CY. Association of pulmonary tuberculosis and ethambutol with incident depressive disorder: a nationwide, population-based cohort study. J Clin Psychiatry. 2015;76(4):e505-11.

26. Kiecolt-Glaser JK, Glaser R. Depression and immune function: central pathways to morbidity and mortality. J Psychosom Res. 2002;53(4):873-6.

27. Pachi A, Bratis D, Moussas G, Tselebis A. Psychiatric morbidity and other factors affecting treatment adherence in pulmonary tuberculosis patients. Tuberc Res Treat. 2013;2012:489865.

28. Mikkelsen RL, Middelboe T, Pisinger C, Stage KB. Anxiety and depression in patients with chronic obstructive pulmonary disease (COPD). A review. Nord J Psychiatry. 2004;58(1):65-70.

29. Lee LY, Tung HH, Chen SC, Fu CH. Perceived stigma and depression in initially diagnosed pulmonary tuberculosis patients. J Clin Nurs. 2017. doi:10.1111/jocn.13837.

30. Cegielski JP, McMurray DN. The relationship between malnutrition and tuberculosis: evidence from studies in humans and experimental animals. Int J Tuberc Lung Dis. 2004;8(3):286-98.

31. Vafaei Z, Mokhtari H, Sadooghi Z, Meamar R, Chitsaz A, Moeini M. Malnutrition is associated with depression in rural elderly population. J Res Med Sci. 2013;18 Suppl 1:S15-9.

32. Guerra M, Prina AM, Ferri CP, Acosta D, Gallardo S, Huang $Y$, Jacob KS, Jimenez Velazquez IZ, Llibre Rodriguez JJ, Liu Z, et al. A comparative cross-cultural study of the prevalence of late life depression in low and middle income countries. J Affect Disord. 2016;190:362-8.

33. Wang $\mathrm{K}$, Lu H, Cheung EF, Neumann DL, Shum DH, Chan RC. "Female preponderance" of depression in non-clinical populations: a meta-analytic study. Front Psychol. 2016:7:1398.

34. Freeman A, Tyrovolas S, Koyanagi A, Chatterji S, Leonardi M, Ayuso-Mateos J, Tobiasz-Adamczyk B, Koskinen S, Rummel-Kluge C, Haro JM. The role of socio-economic status in depression: results from the COURAGE (aging survey in Europe). BMC Public Health. 2016:16:1098.

35. Mathew AR, Hogarth L, Leventhal AM, Cook JW, Hitsman B. Cigarette smoking and depression comorbidity: systematic review and proposed theoretical model. Addiction. 2017;112(3):401-12. 
36. Mommersteeg PM, Herr R, Pouwer F, Holt RI, Loerbroks A. The association between diabetes and an episode of depressive symptoms in the 2002 World Health Survey: an analysis of 231,797 individuals from 47 countries. Diabet Med. 2013;30(6):e208-14.

37. Jeon CY, Murray MB. Diabetes mellitus increases the risk of active tuberculosis: a systematic review of 13 observational studies. PLoS Med. 2008;5(7):e152.

38. Popkin BM. Nutrition transition and the global diabetes epidemic. Curr Diab Rep. 2015;15(9):64

39. Badescu SV, Tataru C, Kobylinska L, Georgescu EL, Zahiu DM, Zagrean AM, Zagrean $\mathrm{L}$. The association between diabetes mellitus and depression. J Med Life. 2016;9(2):120-5.

40. Aydin 10 , Ulusahin A. Depression, anxiety comorbidity, and disability in tuberculosis and chronic obstructive pulmonary disease patients: applicability of GHQ-12. Gen Hosp Psychiatry. 2001;23(2):77-83.

41. Kisely S, Crowe E, Lawrence D. Cancer-related mortality in people with mental illness. JAMA Psychiat. 2013;70(2):209-17.

42. Trivedi MH, Greer TL. Cognitive dysfunction in unipolar depression: implications for treatment. J Affect Disord. 2014;152-154:19-27.

43. Janmeja AK, Das SK, Bhargava R, Chavan BS. Psychotherapy improves compliance with tuberculosis treatment. Respiration. 2005;72(4):375-80.

44. Acha J, Sweetland A, Guerra D, Chalco K, Castillo H, Palacios E. Psychosocial support groups for patients with multidrug-resistant tuberculosis: five years of experience. Glob Public Health. 2007;2(4):404-17.

45. Demissie M, Getahun H, Lindtjørn B. Community tuberculosis care through "TB clubs" in rural North Ethiopia. Soc Sci Med. 2003;56(10):2009-18.

46. Tola HH, Shojaeizadeh D, Tol A, Garmaroudi G, Yekaninejad MS, Kebede A, Ejeta LT, Kassa D, Klinkenberg E. Psychological and educational intervention to improve tuberculosis treatment adherence in ethiopia based on health belief model: a cluster randomized control trial. PLoS One. 2016;11(5): e0155147.

47. Aghanwa HS, Erhabor GE. Demographic/socioeconomic factors in mental disorders associated with tuberculosis in southwest Nigeria. J Psychosom Res. 1998;45(4):353-60

48. Reynolds CFR, Patel V. Screening for depression: the global mental health context. World Psychiatry. 2017;16(3):316-7.

49. Chishinga N, Kinyanda E, Weiss HA, Patel V, Ayles H, Seedat S. Validation of brief screening tools for depressive and alcohol use disorders among TB and HIV patients in primary care in Zambia. BMC Psychiatry. 2011;11:75.

50. Baral SC, Karki DK, Newell JN. Causes of stigma and discrimination associated with tuberculosis in Nepal: a qualitative study. BMC Public Health. 2007;7:211.

51. Sherr L, Cluver L. World Health Day focus on HIV and depression - a comorbidity with specific challenges. J Int AIDS Soc. 2017;20(1):21956.

52. Joshi R, Reingold AL, Menzies D, Pai M. Tuberculosis among health-care workers in low- and middle-income countries: a systematic review. PLoS Med. 2006;3(12):e494.

53. Mason PH, Sweetland AC, Fox GJ, Halovic S, Nguyen TA, Marks GB. Tuberculosis and mental health in the Asia-Pacific. Australas Psychiatry. 2016;24(6):553-5.

\section{Submit your next manuscript to BioMed Central and we will help you at every step:}

- We accept pre-submission inquiries

- Our selector tool helps you to find the most relevant journal

- We provide round the clock customer support

- Convenient online submission

- Thorough peer review

- Inclusion in PubMed and all major indexing services

- Maximum visibility for your research

Submit your manuscript at www.biomedcentral.com/submit 